\title{
The Research on Internet-Based Practice Teaching of E-Commerce Applied Undergraduate Talents
}

\author{
Xianyong Meng ${ }^{\mathrm{a}}$, Yiqi Xiong ${ }^{\mathrm{b}}$, Xiangyu Meng ${ }^{\mathrm{c}}$ \\ Zhuhai College of Jilin University, Zhuhai, China \\ ànen_xianyong@hotmail.com, ${ }^{\text {b}}$ Yiqicolin@126.com, \\ 'Meng_marc@aliyun.com
}

\author{
Zhengbo Wang \\ Department of Economics and Related Studies, University \\ of York, York, UK \\ Wang_zhengbo@hotmail.com
}

\begin{abstract}
Education management platform based on Internet and informatization to carry out education and teaching research has always been the focus of modern pedagogy research, which is also one of the important research topics of higher education in the "twelfth five-year" development plan among China and Guangdong province. To make full use of the high quality education resources of Internet, this paper is to specify carrying out the electronic commerce practice teaching based on Internet platform, clearly identify the feasibility, scientificity, applicability and advancement of ecommerce applied talents cultivation, and design electronic commerce practice teaching methods and management standards. At the same time, according to the "twelfth fiveyear" development plan of electronic commerce in Guangdong province and development advantages of electronic commerce in "Pearl River Delta" area, as well as the demand on electronic commerce talents of foreign trade enterprises, it is needed to formulate correct practice teaching training goal of electronic commerce, make full use of the high quality education resources of Internet, and establish the guidance mechanism of independent learning, incentive mechanism of innovation, and the cultivation mechanism of entrepreneurship in the process of practice teaching.
\end{abstract}

Keywords-electronic commerce; practice teaching; reverse teaching method; high quality education resource; applied talents

\section{INTRODUCTION}

To improve the teaching quality of higher education is the common requirements of long-term plan for education reform and development of our country and Guangdong province (2010-2020). Education management platform based on Internet and informatization to carry out education and teaching research has always been the focus of modern pedagogy research, which is also main way to improve teaching quality through making full use of high quality education resources of Internet. At the same time, it is the basic requirements of comprehensive development ecommerce applications in Guangdong Province to carry out electronic commerce applied undergraduate talents practice teaching research based on the Internet platform [1]. During the period of "11th five-year plan", Guangdong province, Yangtze river delta, and Beijing-Tianjin-Tangshan region have become the three growth poles of China's e-commerce development, which present the characteristics of specialization, scale development, agglomeration. Ecommerce and other industries speed up the convergence, which boosts the economic structural adjustment and industrial transformation and upgrading. Guangzhou and Shenzhen have become the national demonstration cities of electronic commerce. Now, a group of leading enterprises agglomeration and cluster trend obvious e-commerce concentrated area has been formed in Guangzhou, Shenzhen, Foshan, Dongguan and other regions. In iron and steel, petrochemical, plastics, food, automobile and electronic industries, there have emerged batches of ecommerce platforms with annual turnover of more than 10 billion yuan. Foreign trade e-commerce has developed rapidly in recent years. Mobile e-commerce has been gradually mature, the number of SMEs applying ecommerce increases rapidly, online shopping is also growing rapidly. To meet the demands on electronic commerce talents of regional economic and social development, improve the quality of the electronic commerce practice teaching, and make full use of high quality education resources of Internet, this paper is to specify carrying out the electronic commerce practice teaching based on Internet platform, clearly identify the feasibility, scientificity, applicability and advancement of ecommerce applied talents cultivation.

From the international view [2][3][4], globalization and information technology have brought new opportunities to the development of electronic commerce in Guangdong province, and international capital investment has also increased on our country's electronic commerce development. Mobile communications, big data, cloud computing and Internet of things technology have provided technical support for e-commerce model innovation, which shows new important development opportunities of ecommerce in Guangdong province.

Domestically speaking, standardization and regional competition have brought new challenges to the development of electronic commerce in Guangdong province. During the "Twelfth five-year" period, the country will under specification of e-commerce development through related policies, laws, regulations, and industry standards [5][6].

Looking from Guangdong province, it is the "world manufacturing industry base", and more than 70 kinds of products production ranks top one in the country. It is also a huge province for consumption and export among the 
country, which laid a solid industrial foundation and consumer base for electronic commerce development. What's more, the development strategy of informatization and industrialization in Guangdong are carried out to meet the urgent need of advantages of e-commerce in the aspects of innovation management pattern, improvement of efficiency of industrial organization, stimulation of market vitality.

Therefore, Internet-based electronic commerce practice teaching can improve the ability of system planning, design, implementation, operation and management of electronic commerce talents. This practice teaching can also improve the students' ability of innovation and entrepreneurship, and even meet the demand of regional economic and social development of electronic commerce talents. However, most of the commercial software of the electronic commerce practice teaching in colleges are doing nothing within the Internet environment and exist independently, which cannot meet the requirements of ecommerce practice teaching [7][8]. So, through the research of developing the electronic commerce practice teaching based on Internet is able to make full use of the high quality education resources of Internet, and establish the guidance mechanism of independent learning, incentive mechanism of innovation, and the cultivation mechanism of entrepreneurship in the process of practice teaching. Besides, carry out "reverse classroom" teaching model of practice teaching, develop the talents in electronic commerce system planning, design, implementation, operation and management, and promote key industries application of electronic commerce in Guangdong province, such as the iron and steel, petrochemical, plastics, food, automobile, electronic information, electrical appliances, ceramics, clothing, furniture, agriculture as well as in culture, tourism, logistics, education, medical services [9][10][11].

\section{The RESEARCH ON PRACTICE TEACHING OF E- COMMERCE}

\section{A. The Study of Practice Teaching Method}

The research on teaching methods of Internet-based electronic commerce practice teaching is to expand the extracurricular teaching space and guide independent study. E-commerce practice teaching is completed through teaching mode of "Reverse Classroom" to implement integration of high quality of network education resources, giving priority to students' independent learning with complementary of teachers' guidance. The teaching methods should be tasks and results-oriented, and combined with periodic teaching evaluation for measurement of teaching quality.

\section{B. The Study of Practice Teaching Management}

The teaching management standards on teaching methods of electronic commerce practice teaching include the standardization of the practice teaching content, modules, projects, assessment, innovation ability cultivating model and business incubation process, etc.

\section{The Study of Practice Teaching Goal}

The first task of Internet-based e-commerce practice teaching is to improve the quality of the practice teaching, and meet the demand on economic and social development of electronic commerce talents. The ultimate goal of ecommerce practice teaching is to cultivate applied talents of e-commerce, as the support of e-commerce applications in "the pearl river delta" region, cross-border e-commerce of international trade enterprises, management model transformation of SMEs and economic structure adjustment and upgrade.

\section{The Study of Innovation and Entrepreneurship Ability Cultivation Mechanism of Practice Teaching}

Internet-based electronic commerce practice teaching promotes the establishment of innovation and entrepreneurship ability cultivation mechanism of ecommerce applied talents. According to the demands on electronic commerce talents of regional economic and social development, a reasonable set of e-commerce practice teaching of the teaching content, teaching methods, teaching goal, management standards, evaluation standards, improves the quality of the electronic commerce practice teaching. Among them, the innovation and entrepreneurship ability cultivation mechanism include the guidance mechanism of independent learning, incentive mechanism of innovation, and the cultivation mechanism of entrepreneurship.

\section{E. Integration of the High Quality Network Education Resources in the Internet}

In-depth research and analysis of the characteristics of the network teaching resources could help effectively integrate e-commerce practice teaching resources in "Ali ecosystem" and "Tencent WeChat platform", and establish electronic commerce practice teaching environment with a complete test system structure, coherent experimental module, clear and specific experiment process. To make full use of the sharing practice teaching resources in the Internet plays a leading role in the electronic commerce practice teaching.

\section{F. The Study of "Reverse Classroom" Teaching Model}

The establishment of the "independent learning guide mechanism" is the key to improve the teaching quality of higher education and the basic requirement of applied undergraduate talents. Using "Reverse classroom" teaching mode to develop electronic commerce practice teaching can stimulate students' enthusiasm and creativity, cultivate the students' consciousness of innovation and entrepreneurship, strengthen the interaction between teachers and students, and make students "active learning and practice" combined with the guidance of the teacher and periodic evaluation. 


\section{RESEARCH METHOD}

\section{A. Clearing Research Purpose and Combing National and Regional Development Plans and Outlines}

Main related programs include:

"The National Medium and Long-term Education Reform and Development Plan Outline (2010-2020)"

"The Long-term Plan for Education Reform and Development of Guangdong Province (2010-2020)"

"Guangdong Province Twelfth Five-year Plan for National Economic and Social Development Program"

"The Twelfth Five-year Development Planning of Ecommerce of Guangdong Province"

\section{B. The Study of "Reverse Classroom" Teaching Model}

It is needed to undertake a research on "Reverse Classroom" teaching model in the electronic commerce practice teaching activities, make appropriate choice of teaching methods, and develop perfect teaching management rules. Internet-based electronic commerce practice teaching can inspire and guide students to do independent learning outside the classroom. Also, it can expand extra-curricular learning space, and develop the students' ability of self-study, innovation and entrepreneurial potential with tasks and performance oriented approach. Teachers focus on electronic commerce practice teaching management through the guidance of the task, performance appraisal, and coaching to achieve "independent learning guidance mechanism", "innovative talent incentive mechanism", "cultivation of entrepreneurial talents mechanism".

\section{Carrying Out Practice Teaching Based on High Quality Education Resources in the Internet}

With effectively integrating e-commerce practice teaching resources in "Ali ecosystem" and "Tencent WeChat platform", it is to establish electronic commerce practice teaching activities with teaching content, teaching method, teaching goal, management rules and evaluation standard. Based on the high quality education resources in "Ali ecosystem" and "Tencent WeChat platform", "Reverse Classroom" teaching model of the electronic commerce practice teaching can be conducted to establish independent learning guidance mechanism, the innovation talents incentive mechanism and the cultivation of entrepreneurial talents mechanism. Through optimizing and integrating network education resources of "Ali ecosystem", "Tencent WeChat platform", "Mooc Class", "Excellent Class", and "national essential class", network teaching platform can be formed with network theory teaching combined with practice teaching. The contents of electronic commerce practice teaching are including: online store registration, release of goods, store operation, shop decoration, online promotion, pre-market and after-sales service and other ecommerce transactions and management work.

\section{Practicing in the Form of Entrepreneurial Teams}

Electronic commerce practice teaching organizes and manages in the form of the team whose size control in 3-5 persons. Members include programmers, copy editors, operations management officers, product supply personnels, etc. Practice teaching in the form of entrepreneurship can help entrepreneurial teams freely select e-commerce trading tools like "Ali ecosystem" and "Tencent WeChat platform", as well as online stores sell commodity categories and brands, depending on the type of online store design and operation. At the same time, relying on backbone courses including WEB Design, WEB Programming, E-commerce Website Construction helps develop e-commerce business practices. Teachers should communicate with entrepreneurial teams regularly to analyze and review the whole team and members according their business reports.

\section{E. Establishing E-Commerce Practice Teaching \\ Evaluation System}

The electronic commerce practice teaching evaluation mechanism includes teaching method evaluation, innovation and entrepreneurial capability assessment, team management capability assessment, the independent learning ability evaluation, teaching achievement evaluation. Through quantitative indicators of innovation ideas, innovation models, innovation achievements, it is precise to do evaluation for electronic commerce practice teaching effects. In addition, it also needs to establish selfevaluation of practice teaching evaluation methods to do scientific and accurate assessment, and to ensure that the evaluation system of continuous improvement.

As a comprehensive evaluation index, online store business performance is utilized to assess team management ability, business operation ability, team innovation and entrepreneurship ability based on "Reverse Classroom" teaching model practice teaching with "Ali ecosystem" and "Tencent WeChat platform".

\section{F. Designing Electronic Commerce Practice Teaching Plan Based on The Internet}

The practice teaching plan mainly includes practice teaching plans of evaluation, team management, entrepreneurial guidance and innovation guidance.

\section{CONCLUSIONS}

It is a practical and low cost of practice teaching management method and the teaching strategy to ecommerce practice teaching based on Internet platform. In this paper, it is identified that the research on e-commerce practice teaching in the form of "Reverse Classroom" is conducted based on the high quality education resources in “Ali ecological system" and "Tencent WeChat platform”. In addition, this paper is to develop management rules related to e-commerce practice teaching, establish independent learning guidance mechanism, the innovation talents incentive mechanism and the cultivation of entrepreneurial talents mechanism, and realize the organization and management of e-commerce practice 
teaching in the form of entrepreneurial team, and finally firmly support the e-commerce applications in "the pearl river delta" region, management model transformation of SMEs and economic structure adjustment and upgrade.

\section{REFERENCES}

[1] Charalambos Y. Charalambous, Andreas Komitis, Maria Papacharalambous, Afroditi Stefanou. 2014. "Using generic and content-specific teaching practices in teacher evaluation: An exploratory study of teachers' perceptions". Teaching and Teacher Education, vol. 41:22-23

[2] Jülide Sarigöl \& Ali Rıza Akdeniz. 2014. "The Effect of the Course of Teaching Practice on Prospective Science Student Teachers' Teaching Methods and Technical Knowledge of the Subject of Electromagnetism". Procedia - Social and Behavioral Sciences,vol. 136: 463-468.

[3] Jenny Yiend, Saranne Weller, Ian Kinchin. 2014. "Peer observation of teaching: The interaction between peer review and developmental models of practice". Journal of Further and Higher Education, vol. 38, issue. 4: 32-35.

[4] Duan Jie, Sun Xian Gang. 2014. "Practice Teaching Method Research Based on Directional Decomposition of Scientific Research Project”. Canadian Social Science,vol. 10: 144-148.

[5] Raja Maznah, Raja Hussain, Aishah Abu Bakar. 2011. "Eye on teaching: improving practice through research inquiries”. Procedia Social and Behavioral Sciences, vol. 9: 403-407.
[6] Duan Chun Mei, Lu Hong Qian. 2014. "Teaching Content Design of Information Management for University Student of E-Commerce Major”. 2014 3rd International Conference on Science and Social Research.vol. 4: 245-250.

[7] Bai Dong Rui. 2011. "Campus E-Commerce Entrepreneurial Mode Analysis”. 2011 International Conference on Management Science and Intelligent Control(ICMSIC 2011) vol. 4:46-50.

[8] Chen Xiao Ming. 2011. "Thoughts on Improving the Effect of ECommerce Experiment Teaching". Conference on Creative Education(CCE2011),vol. 5: 230-234.

[9] Wang Wei Wei, Nan Yang, Qi Jing Jia. 2012. “A research on Based on the Skills Competition of the Electronic Commerce Professional Students' Practice Ability Training”. 2012 International Conference on Education Reform and Management Innovation(ERMI 2012). vol. 3: $132-135$.

[10] Sun Jian Hong, Lan Geng Ze. 2013. "Research on Innovation Teaching Mode of Course-Based on Entrepreneurial Capabilities Perspective". 2013 International Conference on Psychology,Management and Social Science(PMSS 2013). vol. 15: 50-55.

[11] Gongbu Gao. 2013. "The Research of Construction for E-commerce Sanchuang Talent'S Education System”. Proceedings of 2013 2nd International Conference on Social Science and Education(ICSSE 2013) vol. 46:31-35 